
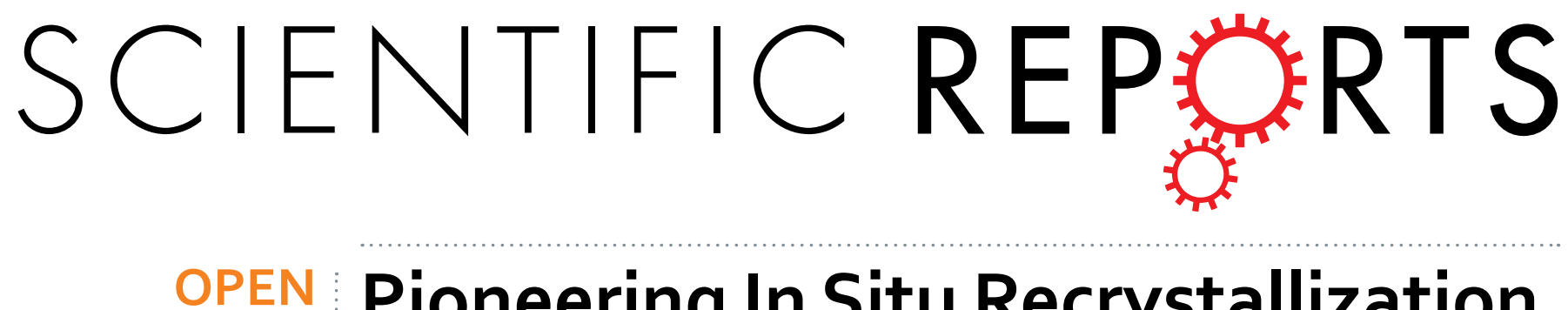

\title{
Pioneering In Situ Recrystallization during Bead Milling: A Top-down Approach to Prepare Zeolite A
}

Received: 11 April 2016

Accepted: 13 June 2016

Published: 05 July 2016

\section{Nanocrystals}

Chokkalingam Anand ${ }^{1}$, Yudai Yamaguchi ${ }^{1}$, Zhendong Liu ${ }^{1}$, Sayoko Ibe ${ }^{1}$, Shanmugam P. Elangovan ${ }^{1}$, Toshihiro Ishii ${ }^{2}$, Tsuyoshi Ishikawa ${ }^{2}$, Akira Endo ${ }^{3}$, Tatsuya Okubo ${ }^{1}$ \& Toru Wakihara ${ }^{1}$

Top-down approach has been viewed as an efficient and straightforward method to prepare nanosized zeolites. Yet, the mechanical breaking of zeolite causes amorphization, which usually requires a post-milling recrystallization to obtain fully crystalline nanoparticles. Herein we present a facile methodology to prepare zeolite nanocrystals, where milling and recrystallization can be performed in situ. A milling apparatus specially designed to work under conditions of high alkalinity and temperature enables the in situ recrystallization during milling. Taking zeolite $A$ as an example, we demonstrate its size reduction from $\sim 3 \mu \mathrm{m}$ to $66 \mathrm{~nm}$ in $30 \mathrm{~min}$, which is quite faster than previous methods reported. Three functions, viz., miniaturization, amorphization and recrystallization were found to take effect concurrently during this one-pot process. The dynamic balance between these three functions was achieved by adjusting the milling period and temperature, which lead to the tuning of zeolite A particle size. Particle size and crystallinity of the zeolite A nanocrystals were confirmed by X-ray diffraction, scanning electron microscopy, transmission electron microscopy and water adsorption-desorption. This work presents a pioneering advancement in this field of nanosized zeolites, and will facilitate the mass production as well as boost the wide applications of nanosized zeolites.

Synthetic zeolites are important candidates for a wide range of industrial applications. They offer unique structural and textural features that can be further modified for specific needs. Recently, numerous techniques have been reported for the effective improvement of these features. Despite numerous research articles and patents dedicated to exploring the various aspects of zeolite synthesis and applications, interests in these areas seem ever expanding, attracting scientists from interdisciplinary fields ${ }^{1-10}$. However, an important area of zeolite research, namely the synthesis of zeolite nanocrystals, has not been tapped to its maximum potential ${ }^{5-13}$.

Compared with their micrometer sized counterparts, zeolite nanocrystals have several unique properties which are related to particle-size-induced diffusional freedom and are essential in the fields of catalysis and separation $^{8-10}$. Owing to their fascinating size variations, zeolite nanocrystals are suitable components for designing environmentally benign and economically viable materials of commercial importance ${ }^{5-13}$. To date, several methods have been developed for the preparation of zeolite nanocrystals, such as template-assisted, colloidal solution, ionothermal, dry gel conversion, microwave, sonochemical, and multistep hydrothermal syntheses. Usually, these methods can be categorized into two approaches: bottom-up and top-down ${ }^{10-18}$. The top-down approach, which forms the core of this study, is highly versatile and does not require the complicated procedures used in bottom-up methods.

In our previous studies, zeolite nanocrystals were synthesized by a two-step, top-down strategy. First, zeolite was milled using zirconia beads of size $300 \mu \mathrm{m}$. The following recrystallization of milled zeolite with dilute aluminosilicate or silicate solutions then led to nanocrystals with high crystallinity. Zeolite A and ZSM-5, exhibiting excellent ion-exchange and catalytic activity, have been successfully prepared by this technique ${ }^{17-19}$. More

${ }^{1}$ The University of Tokyo, Department of Chemical System Engineering, Tokyo, 113-8656, Japan. ${ }^{2}$ Ashizawa Finetech Ltd., Akanehama 1-4-2, Narashino, Chiba, 275-8572, Japan. ${ }^{3}$ National Institute of Advanced Industrial Science and Technology (AIST), Ibaraki 305-8565, Japan. Correspondence and requests for materials should be addressed to T.W. (email: wakihara@chemsys.t.u-tokyo.ac.jp) 


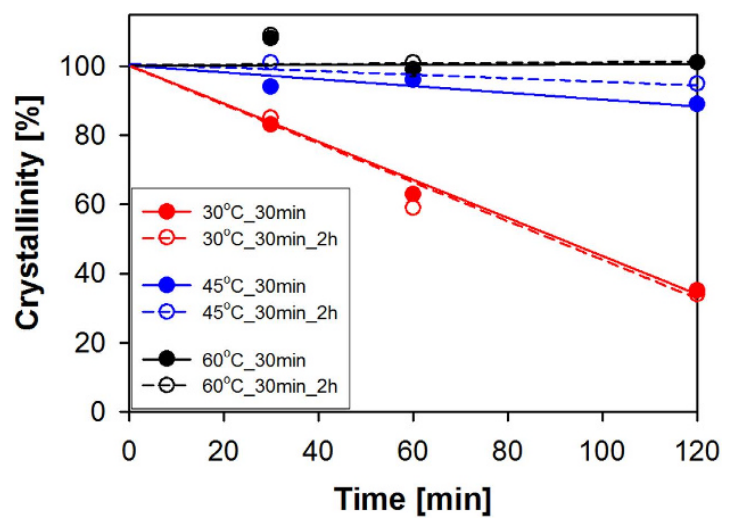

Figure 1. Influence of temperature and external recrystallization on the crystallinity of $x^{\circ} \mathrm{C} \_30 \mathrm{~min}$ and $\mathrm{x}^{\circ} \mathrm{C} \_30 \mathrm{~min} \_2 \mathrm{~h}$ samples.

importantly, a simplification to achieve a higher yield of zeolite A nanocrystals per batch was also introduced, wherein the aluminosilicate solution was replaced with aqueous $\mathrm{NaOH}^{19}$. Similarly, an ultrafast version of this top-down approach using tubular reactors to prepare SSZ-13 and $\mathrm{AlPO}_{4}-5$ nanocrystals within a few minutes has been realized ${ }^{20}$.

Inspired by our previous studies, we report a novel yet simple approach for the production of zeolite A nanocrystals that uses a three-integrated factors viz., amorphization, miniaturization and recrystallization. The approach involves an improved method for the reduction of particle size using in situ recrystallization during bead milling with aqueous $\mathrm{NaOH}$. This method represents a substantial improvement to our previously reported approach of bead milling followed by post-milling recrystallization ${ }^{17-20}$. Zirconia beads with a diameter of $500 \mu \mathrm{m}$ were used to inflict partial structural collapse on zeolite A particles inside an apparatus specially designed to operate under conditions of high alkalinity $(\mathrm{pH} \sim 14)$ and different temperatures $\left(30-60^{\circ} \mathrm{C}\right)$. The thermal stimulation within the milling medium and its alkaline nature simultaneously trigger the recrystallization process, which shapes the milled zeolite A particles into high crystallinity nanocrystals. Since the entire process of in situ recrystallization during bead milling takes merely $30 \mathrm{~min}$, it is more attractive for large-scale production than its predecessors (Table S1, Supporting Information).

Three series of zeolite A nanocrystals, prepared using various temperatures and milling times, have been explored to determine the reliability of the in situ recrystallization method. The two general nomenclatures $x^{\circ} \mathrm{C} \_y \min$ and $x^{\circ} \mathrm{C} \_y \min \_2 \mathrm{~h}$ to differentiate samples are based on the milling temperature, time and additional external recrystallization for $2 \mathrm{~h}$ when applied (Methods, Supporting Information) respectively. Table S2 shows the list of studied samples and their crystallinity, average particle size and yield. Note that the percentage crystallinity of all samples was calculated by comparing their respective X-ray diffraction (XRD) peak areas with that of raw zeolite A (Equation S1, Supporting Information), and the average particle size was estimated using scanning electron microscopy (SEM) images. The yield of the final products was calculated using Equation S2 (Supporting Information). A schematic representation of the in situ recrystallization during bead milling is depicted in Figure S1.

\section{Results and Discussions}

Figure 1 shows the influence of temperature and external recrystallization on the crystallinity of the $x^{\circ} \mathrm{C} \_30$ min samples under investigation. At a processing temperature of $30^{\circ} \mathrm{C}$, the crystallinity of the samples was considerably low, indicating that the in situ recrystallization is neither proceeding nor noticeably faster at low temperature. This result is consistent with the previous studies because the mechanical force due to bead milling crushed the zeolite A crystals into small pieces but also caused amorphization. In an attempt to restore the crystallinity, an external recrystallization performed outside of the milling apparatus was also conducted using the same alkaline medium and temperature. However, no significant improvement of crystallinity was obtained at $30^{\circ} \mathrm{C}$, even though an external recrystallization time of $2 \mathrm{~h}$ was employed, indicating that at low temperature recrystallization proceeds at an unnoticeably slower rate. However, an increase in crystallinity was observed as the temperature was increased from $30^{\circ} \mathrm{C}$ to $45^{\circ} \mathrm{C}$ and to $60^{\circ} \mathrm{C}$. This result demonstrates that the rate of in situ recrystallization is indeed faster at elevated temperatures. For comparison, the external recrystallization was also performed on the $45^{\circ} \mathrm{C} \_30 \mathrm{~min}$ and $60^{\circ} \mathrm{C} \_30 \mathrm{~min}$ samples, which generated samples named $45^{\circ} \mathrm{C} \_30 \mathrm{~min} \_2 \mathrm{~h}$ and $60^{\circ} \mathrm{C} \_30 \mathrm{~min} \_2 \mathrm{~h}$ samples, respectively. As observed in Fig. 1, almost no improvement in crystallinity was observed for the $45^{\circ} \mathrm{C} \_30 \mathrm{~min} \_2 \mathrm{~h}$ and $60^{\circ} \mathrm{C} \_30 \mathrm{~min} \_2 \mathrm{~h}$ samples, probably because the in situ recrystallization at these temperatures was adequate to reconstruct the damage caused by bead milling.

As a first step towards optimizing the in situ recrystallization during bead milling, we studied the influence of milling time by increasing it from 30 to $120 \mathrm{~min}$ at $30^{\circ} \mathrm{C}$. Figures $\mathrm{S} 2$ and $\mathrm{S} 3$ show the powder XRD patterns and SEM images of the $30^{\circ} \mathrm{C} \_y$ min and $30^{\circ} \mathrm{C} \_y$ min_2 $\mathrm{h}$ samples. Evaluation of the XRD peaks reveals a drastic decrease in crystallinity from $83 \%$ to $35 \%$, and SEM images show a decrease in particle size from $143 \mathrm{~nm}$ to $117 \mathrm{~nm}$ (Table S2). Increasing the time from 30 to $120 \mathrm{~min}$ causes the formation of higher fractions of non-crystalline portion i.e. lower crystallinity in the $30^{\circ} \mathrm{C} \_y$ min samples (Figure S1a and Table S2). Furthermore, the set temperature, i.e. $30^{\circ} \mathrm{C}$, seems extremely low for promoting the rate of in situ recrystallization. Thus, it was only possible to produce zeolite A nanocrystals with low crystallinity when the time was increased. This result 
is consistent with that of the $30^{\circ} \mathrm{C} \_y$ min_2 $\mathrm{h}$ samples, wherein the crystallinity (Figure S2a) and particle size (Figure S3) remain essentially unchanged even after $2 \mathrm{~h}$ external recrystallization (Table S2). Since the process of recrystallization was apparently slower at $30^{\circ} \mathrm{C}$ despite increasing the time from 30 to $120 \mathrm{~min}$, the same set of experiments was conducted at elevated temperatures $\left(45\right.$ and $\left.60^{\circ} \mathrm{C}\right)$. Thereby, the individual and combined roles of temperature and milling time in promoting the in situ recrystallization can be clarified.

Figure 2a,b show the powder XRD patterns and SEM images of $x^{\circ} \mathrm{C} \_30 \mathrm{~min}$ samples prepared at different temperatures. A substantial increase in crystallinity from $83 \%$ to $108 \%$ was achieved by increasing the temperature from 30 to $60^{\circ} \mathrm{C}$ (Fig. 2a). Increasing the temperature also decreased the particle size of zeolite A nanocrystals, as evidenced through the SEM images in Fig. 2b. Figure $2 \mathrm{c}$ shows the variations in particle size distribution calculated from SEM images of the $x^{\circ} \mathrm{C}_{-} 30 \mathrm{~min}$ samples. Though particle size analyzer is considered a specialized technique for measuring particle size, we chose SEM, because of the agglomeration in our samples. The process of recovering the zeolite A nanocrystals from the slurry by washing and drying has led to the capillary force and to the interparticle interactions such as the electrostatic one and the condensation of silanol groups, which resulted in agglomeration. Agglomeration is expected to interfere with the size distribution data, if analysed using particle size analyzer. In order to study the extent of agglomeration, $60^{\circ} \mathrm{C} \_30 \mathrm{~min}$ sample was characterized using particle size analyzer over a Shimadzu SALD-7500 and the results are shown in Figure S4 (supporting information). As expected the agglomeration interfered with the particle size data of the $60^{\circ} \mathrm{C} \_30 \mathrm{~min}$ sample (Figure S4a). Therefore, prior to particle size analysis, jet milling was used to disperse the agglomerated zeolite A nanocrystals of $60^{\circ} \mathrm{C} \_30 \mathrm{~min}$ sample. Figure $\mathrm{S} 4 \mathrm{~b}$ shows the particle size data of the $60^{\circ} \mathrm{C} \_30 \mathrm{~min}$ sample that was dispersed under jet milling, which is quite different from Figure S4a. Even after jet milling the agglomeration can still be found from Figure S4b, which indicates that SEM is suitable for obtaining particle size data in samples with agglomeration.

Apart from higher crystallinity and smaller particle size, the increase in temperature led to highly uniform particle size distribution. At $30^{\circ} \mathrm{C}$, complete control over particle size was difficult to achieve as particles ranging from 60 to $500 \mathrm{~nm}$ were produced. However, increasing the temperature to $60^{\circ} \mathrm{C}$ enabled production of a uniform size distribution with an average of $66 \mathrm{~nm}$. Note that downsizing zeolite A to highly crystalline particles of uniform size required only $30 \mathrm{~min}$ of in situ recrystallization during bead milling, which is noticeably faster than its predecessors shown in Table S1 (Supporting Information). The influences of time and external recrystallization on the crystallinity, particle size and yield of the $45^{\circ} \mathrm{C} \_y$ min and $60^{\circ} \mathrm{C} \_y$ min samples were tested and their results are summarized in Figures S5, S6, S7 and S8 and Table S2 (Supporting Information). Unlike the $30^{\circ} \mathrm{C}_{-} y \mathrm{~min}$ samples, the decrease in the crystallinity of the $45^{\circ} \mathrm{C} \_y$ min and $60^{\circ} \mathrm{C}_{-} y \mathrm{~min}$ samples caused by time variation is relatively small. Furthermore, they exhibited relatively enhanced particle size and crystallinity.

The results indicate that at elevated temperatures, the mobility of the aluminosilicate species in the aqueous $\mathrm{NaOH}$ solution is more pronounced, leading to faster recrystallization and faster particle-size reduction as well as narrower size distribution. The extent of damage to the zeolite A lattice was evaluated by comparing the transmission electron microscopy (TEM) image of a sample milled for $30 \mathrm{~min}$ without in situ recrystallization with those of the $x^{\circ} \mathrm{C} \_30 \mathrm{~min}$ samples (Fig. 3). Figure 3a clearly shows the occurrence of non-crystalline zeolite A particles in response to $30 \mathrm{~min}$ of bead milling, whereas Fig. 3b,c,d show the highly crystalline array of micropores produced from the damaged zeolite A particles as a result of in situ recrystallization during bead milling. The water vapour adsorption-desorption isotherms of the raw, bead milled, i.e. zeolite A bead milled without the in situ recrystallization, and $x^{\circ} \mathrm{C} \_30 \mathrm{~min}$ samples are shown in Fig. 4.

All samples exhibited type I isotherms characteristic of water vapour adsorption onto hydrophilic zeolite A micropores. The variation in the amount of water vapour adsorbed onto the analyzed samples reflects the differences in the degrees of their crystallinity and the particle size. In particular, the amount adsorbed by the 30 min milled sample (i.e. the sample bead milled without the in situ recrystallization) is substantially less than that adsorbed by the raw and $\mathrm{x}^{\circ} \mathrm{C} \_30$ min samples because of the partial loss of crystallinity caused by the milling treatment. The amount of water adsorbed by $\mathrm{x}^{\circ} \mathrm{C} \_30 \mathrm{~min}$ samples at high relative pressures increased with temperature, indicating that water molecules adsorbed onto external surfaces and condensed in the interparticle voids of the nanosized samples. These results are in good agreement with the TEM results and demonstrate that increasing the temperature from 30 to $60^{\circ} \mathrm{C}$ allows the particle size and crystallinity of zeolite A nanocrystals treated for $30 \mathrm{~min}$ to be tuned. The potential of in situ recrystallization during bead milling for the faster production of zeolite A nanocrystals has been compared with other established methods ${ }^{13,21-23}$ (Table S1, Supporting Information). Table S1 confirms that the formation of zeolite A nanocrystals by our method is the fastest. Our method also shows better yield and more uniform particle size than the other techniques.

The mechanism observed for our top-down in situ recrystallization is somehow expected to be different from the bottom-up zeolite crystallization reported by Valtchev et al. In their bottom-up approach, Valtchev et al. carefully studied the crystallization kinetics under ambient temperature conditions, and proposed a mechanism for bottom-up formation, which views that the nucleation is initiated by an extensive exchange of species between solid and liquid phases during the induction period, and then crystal growth follows by an Ostwald ripening of the crystals ${ }^{24,25}$. However, in our opinion and from previous post-milling experiments, we postulate the following mechanism for the in situ recrystallization during bead milling. Prior to the milling, raw zeolite A is dispersed in $2 \mathrm{M} \mathrm{NaOH}$ solution by agitation for $20 \mathrm{~min}$. During this period the zeolite A slightly dissolves to form the interactive species; that is aluminosilicate solution. The resulting aluminosilicate solution is expected to be in a state of equilibrium for the in situ recrystallization under bead milling at suitable temperatures. During the bead milling treatment a large number of crystallites were formed. The crystallites act as potential seeds for the in situ recrystallization, resulting in zeolite A nanocrystals with high crystallinity. However, the decrease in crystallinity of the $30^{\circ} \mathrm{C} \_y$ min samples despites extending the bead milling time from 30 to $120 \mathrm{~min}$, indicates that at lower temperature milling is more predominant than crystal growth (Table S2 and Figure S2). In this regard, an ex situ post-milling recrystallization was performed at $30^{\circ} \mathrm{C}$ using $30 \mathrm{~min}$ milled zeolite A powder for extended period of 
a

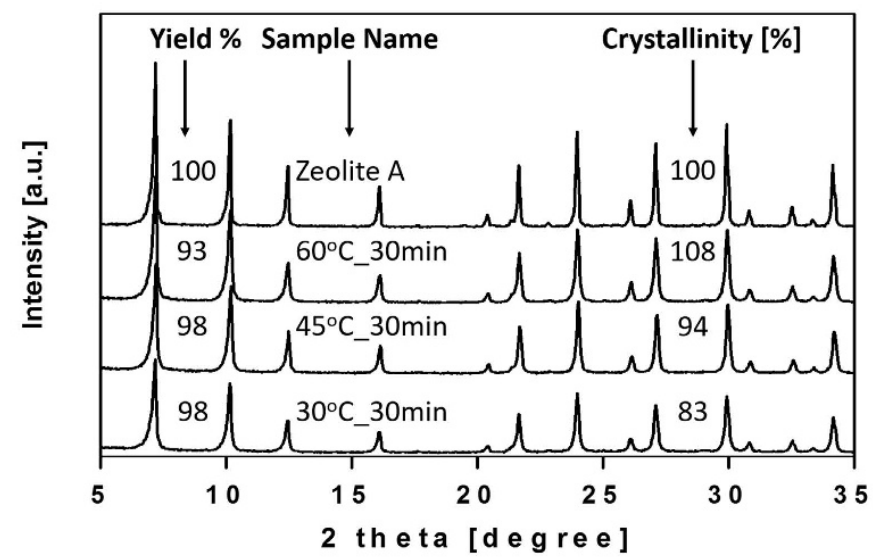

b
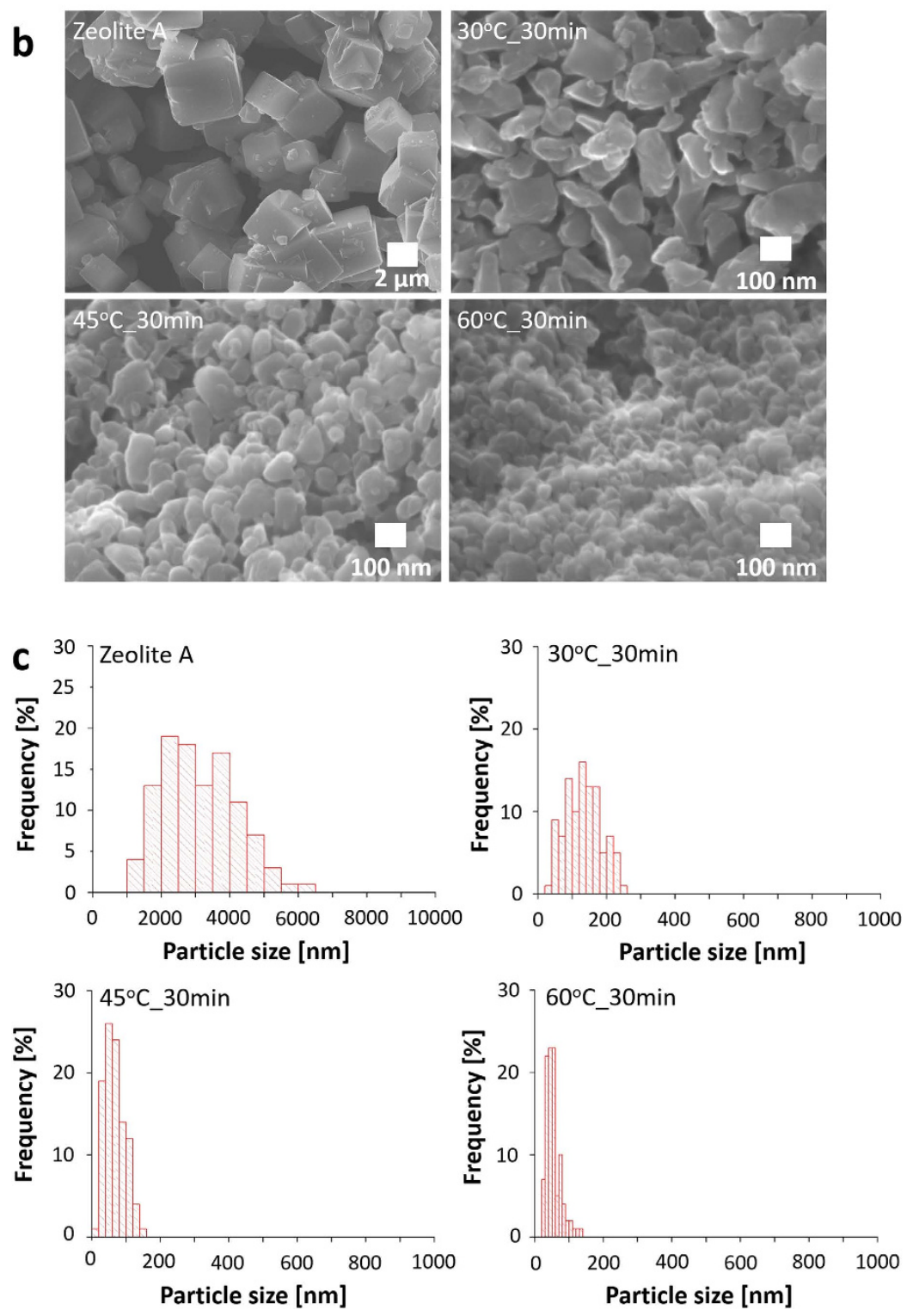

Figure 2. Influence of temperature on the crystallinity of $\mathrm{x}^{\circ} \mathrm{C} \_30 \mathrm{~min}$ samples: (a) powder XRD patterns. (b) SEM images. (c) particle size distribution histograms. 

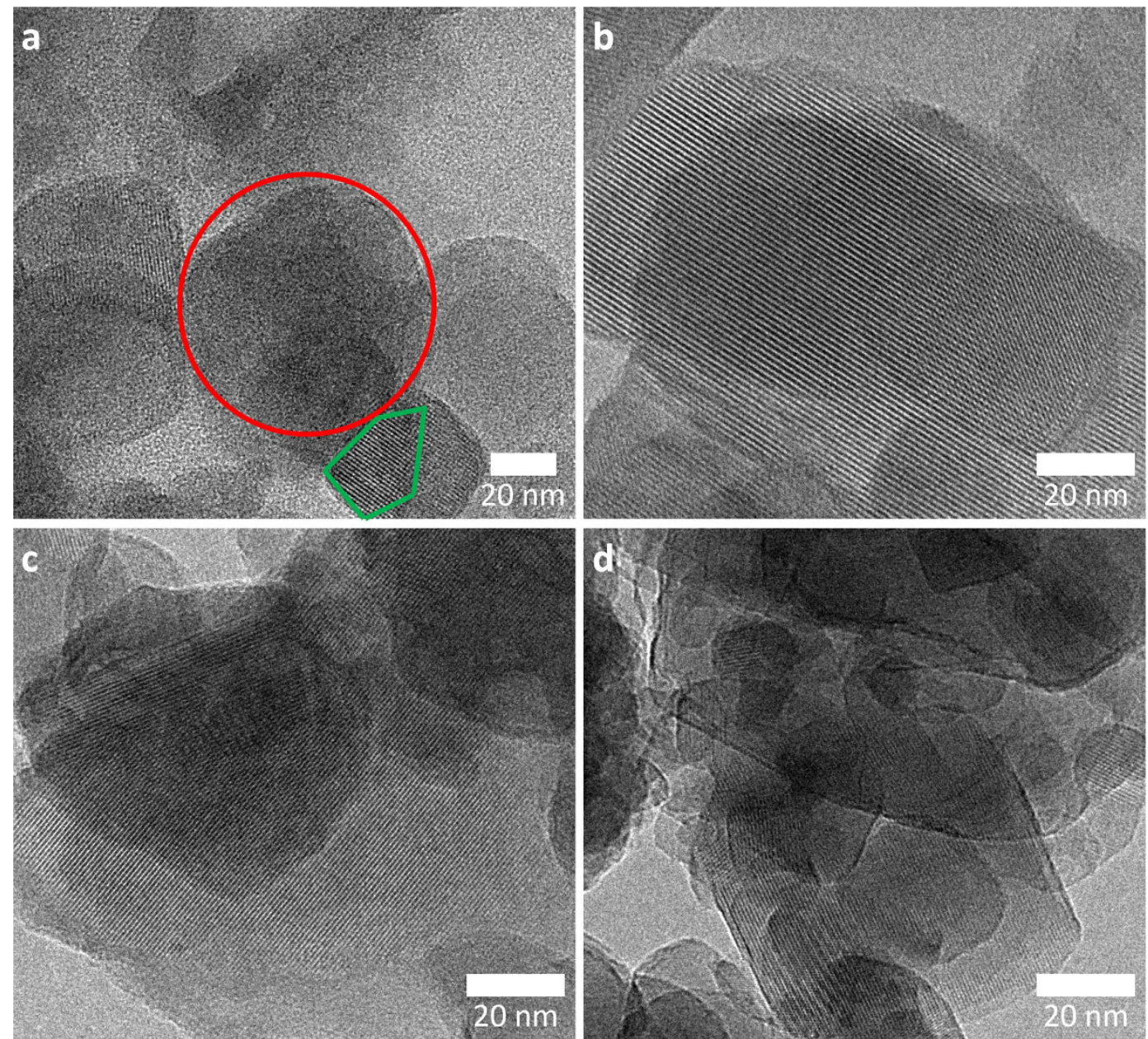

Figure 3. TEM images: (a) 30 min milled zeolite A (i.e. zeolite A beadmilled without the in situ recrystallization; non-crystalline and crystalline particles are indicated within the red and green areas, respectively). (b) $30^{\circ} \mathrm{C} \_30 \mathrm{~min}$; (c), $45^{\circ} \mathrm{C} \_30 \mathrm{~min}$; (d) $60^{\circ} \mathrm{C} \_30 \mathrm{~min}$.

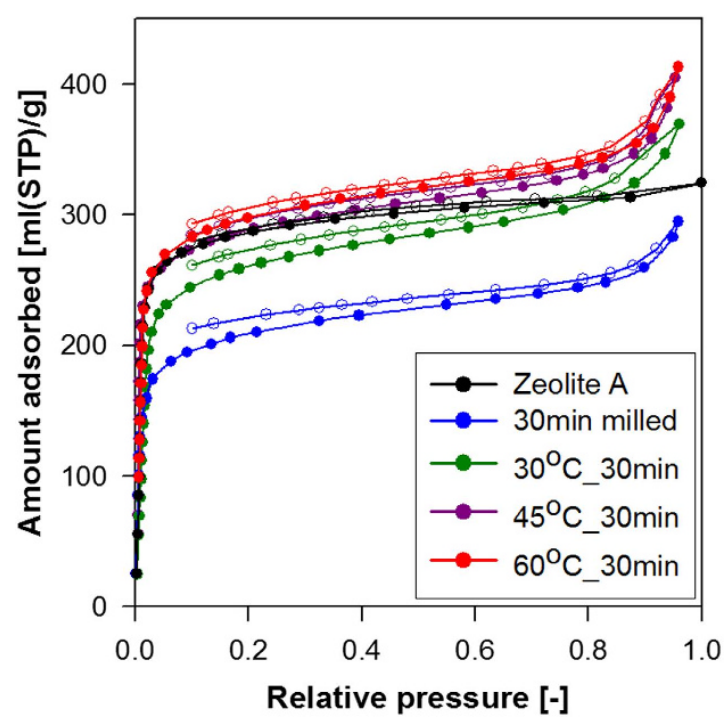

Figure 4. Water vapour adsorption-desorption isotherms of raw, $30 \mathrm{~min}$ milled (i.e. zeolite A bead milled without in situ recrystallization) and $x^{\circ} \mathrm{C} \_30 \mathrm{~min}$ zeolite A samples (' $\bullet$ ' indicates adsorption branch of isotherm and ' $O$ 'desorption branch of isotherm). 
time with $2 \mathrm{M} \mathrm{NaOH}$. Figure $\mathrm{S} 9$ shows the crystallinity of the $30 \mathrm{~min}$ milled sample at $30^{\circ} \mathrm{C}$ as a function of time. As can be seen from Figure S9, nearly $24 \mathrm{~h}$ of post-milling recrystallization at $30^{\circ} \mathrm{C}$ is required for achieving $100 \%$ crystallinity for the $30 \mathrm{~min}$ milled sample. The result confirmed that the in situ recrystallization is in fact proceeding at $30^{\circ} \mathrm{C}$; however, its rate is unnoticeably slow as compared to the dominant milling process. Therefore, elevating the temperature from 30 to $60^{\circ} \mathrm{C}$ contributes to the higher mobility of aluminosilicate species which greatly improves the rate of in situ recrystallization. These results suggest that our in situ recrystallization mechanism is kinetically driven to a larger extent.

\section{Conclusions}

In summary, we have developed a strategy for producing zeolite A nanocrystals in a very short period of time, which involves in situ recrystallization during bead milling. Since control over the particle size and crystallinity of zeolite A nanocrystals was established by simply adjusting the temperature, the whole process seems to be kinetically driven. Under the right set of condtions (i.e. $30 \mathrm{~min}$ at $60^{\circ} \mathrm{C}$ ), in situ recrystallization during bead milling holds great potential for the faster preparation of zeolite A nanocrystals with high crystallinity. This facile methodology can serve as a new platform to prepare zeolite nanocrystals that might address issues cutting across a wide range of disciplines, such as catalysis, semiconductors, and drug delivery.

\section{Experimental Section}

In situ recrystallization during bead milling. In a typical milling experiment, commercial zeolite A (4A, LTA-type zeolite, $\mathrm{Si} / \mathrm{Al}=1.0$, cation: $\mathrm{Na}^{+}$, Tosoh Co., Japan) was ground inside a milling apparatus (modified LMZ015 Ashizawa Finetech Ltd., Tokyo, Japan with an internal volume of $0.15 \mathrm{~L}$ ) specially equipped to operate under conditions of high alkalinity $(\mathrm{pH} \sim 14)$ and packed with $485 \mathrm{~g}$ of $\mathrm{ZrO}_{2}$ beads of diameter $500 \mu \mathrm{m}$; the mill was operated at a rotation speed of $3000 \mathrm{rpm}$. Prior to milling, $50 \mathrm{~g}$ of zeolite A was dispersed in $500 \mathrm{~mL}$ of $2 \mathrm{M}$ $\mathrm{NaOH}$ solution. Each experiment was performed for $2 \mathrm{~h}$ and samples were collected at regular intervals of $30 \mathrm{~min}$, $60 \mathrm{~min}$, and $120 \mathrm{~min}$. The experiments were repeated at various different temperatures $\left(30^{\circ} \mathrm{C}, 45^{\circ} \mathrm{C}\right.$, and $\left.60^{\circ} \mathrm{C}\right)$.

\section{References}

1. Davis, M. E. \& Lobo, R. F. Zeolite and molecular sieve synthesis. Chem. Mater. 4, 756-768 (1992).

2. Kirschhock, C. E. A. et al. Zeosil nanoslabs: building blocks in $\mathrm{nPr}_{4} \mathrm{~N}^{+}$-mediated synthesis of MFI zeolite. Angew. Chem. Int. Ed. 40, 2637-260 (2001).

3. Maesan, Th. L. M. \& Marcus, B. Introduction to Zeolite Science and Practice in Studies Surf. Sci. Catal. $2^{\text {nd }}$ edn, Vol. 137 (eds van Bekkum, H., Flanigen, E. M., Jacobs, P. A. \& Jansen, J. C.) Ch. 1, 1-2 (Elsevier, 2001).

4. Biemmi, E. \& Bein, T. Assembly of nanozeolite monolayers on the gold substrates of piezoelectric sensors. Langmuir 24, 11196-11202 (2008).

5. Rhodes, C. J. Zeolite mediated reactions: mechanistic aspects and environmental applications. Prog. React. Kinet. Mech. 33, 1-79 (2008).

6. Mintova, S., Olson, N. H., Senker, J. \& Bein, T. Mechanism of the transformation of silica precursor solutions into Si-MFI zeolite. Angew. Chem. Int. Ed. 41, 2558-2561 (2002).

7. Camblor, M. A., Corma, A. \& Valencia, S. Characterization of nanocrystalline zeolite beta. Micropor. Mesopor. Mater. 25, 59-74 (1998).

8. Valtchev, V. \& Tosheva, L. Porous nanosized particles: preparation, properties, and applications. Chem. Rev. 113, 634-6760 (2013).

9. Tosheva, L. \& Valtchev, V. Nanozeolites: synthesis, crystallization mechanism and applications. Chem. Mater. 17, 2494-2513 (2005).

10. Wakihara, T. \& Tatami, J. Top-down tuning of nanosized zeolites by bead-milling and recrystallization. J. Jpn. Petrol. Inst. 56, 206-213 (2013).

11. Majano, G., Borchardt, L., Mitchell, S., Valtchev, V. \& Ramirez, J. Rediscovering zeolite mechanochemistry - a pathway beyond current synthesis and modification boundaries. Micropor. Mesopor. Mater. 194, 106-114 (2014).

12. Hirota, Y. et al. Dry gel conversion synthesis of SAPO-34 nanocrystals. Mat. Chem. Phys. 123, 507-509 (2010).

13. Awala, H. et al. Template-free nanosized faujasite-type zeolites. Nat. Mater. 14, 447-451 (2015).

14. Mintova, S., Gilson, J. P. \& Valtchev, V. Advances in nanosized zeolites. Nanoscale 5, 6693-6703 (2013).

15. Álvaro-Muñoz, T., Sastre, E. \& Márquez-Álvarez, C. Microwave-assisted synthesis of plae-like SAPO-34 nanocrystals with increased catalyst lifetime in the methanol-to-olefin reaction. Catal. Sci. Technol. 4, 4330-339 (2014).

16. Yang, M. et al. A top-down approach to prepare silicoaluminophosphate molecular sieve nanocrystals with improved catalytic activity. Chem. Comm. 50, 1845-1847 (2014).

17. Wakihara, T. et al. Bead-milling and postmilling recrystallization: an organic template-free methodology for the production of nano-zeolites. Cryst. Growth Des. 11, 955-958 (2011).

18. Wakihara, T. et al. Preparation of nano-zeolite X by bead-milling and post-milling recrystallization. J. Ceram. Soc. Japan 120, 341-343 (2012).

19. Wakihara, T. et al. Facile synthesis of nano-sized zeolite by recrystallization of milled zeolite with small amount of $\mathrm{NaOH}$ solution. Adv. Porous Mater. 1, 214-218 (2013).

20. Liu, Z. et al. A top-down methodology for ultrafast tuning of nanosized zeolites. Chem. Commun. 51, 12567-12570 (2015).

21. Mintova, A. S., Olson, N. H., Valtchev, V. \& Bein, T. Mechanism of zeolite A nanocrystal growth from colloids at room temperature. Science 283, 958-960 (1999).

22. Song, W., Li, G., Grassian, V. H. \& Larsen, S. C. Development of improved materials for environmental applications: nanocrystalline NaY zeolites. Environ. Sci. Technol. 39, 1214-1220 (2005).

23. Valtchev, V., Tosheva, L. \& Bozhiolv, K. N. Synthesis of zeolite Nanocrystals at room temperature. Langmuir 21, 10724-10729 (2005).

24. Valtchev, V. \& Bozhilov, K. N. Transmission electron microscopy study of the formation of FAU-type zeolite at room temperature. J. Phys. Chem. B. 108, 15587-15598 (2004).

25. Melinte, G. et al. 3D study of the morphology and dynamics of zeolite nucleation. Chem. Eur. J. 21, 18316-18327 (2015).

\section{Acknowledgements}

This work was supported in part by a Grant for Advanced Industrial Technology Development (2011) from the New Energy and Industrial Technology Development Organization of Japan. 


\section{Author Contributions}

C.A., Y.Y., T.I. and T.I. conducted the experiments. C.A., Y.Y., Z.L., S.I. and S.P.E. analyzed the results. E.A. conducted the water adsorption-desorption experiments and interpreted the data, C.A. wrote the manuscript. T.O. and T.W. corrected the manuscript and supervised the project.

\section{Additional Information}

Supplementary information accompanies this paper at http://www.nature.com/srep

Competing financial interests: The authors declare no competing financial interests.

How to cite this article: Anand, C. et al. Pioneering In Situ Recrystallization during Bead Milling: A Top-down Approach to Prepare Zeolite A Nanocrystals. Sci. Rep. 6, 29210; doi: 10.1038/srep29210 (2016).

(c) (i) This work is licensed under a Creative Commons Attribution 4.0 International License. The images or other third party material in this article are included in the article's Creative Commons license, unless indicated otherwise in the credit line; if the material is not included under the Creative Commons license, users will need to obtain permission from the license holder to reproduce the material. To view a copy of this license, visit http://creativecommons.org/licenses/by/4.0/ 